\title{
Article
}

\section{Reflecting on Assessment: Strategies and Tools for Measuring the Impact of a Canadian WAC Program}

\author{
Michael Kaler \\ University of Toronto Mississauga \\ Tyler Evans-Tokaryk \\ University of Toronto Mississauga
}

\section{Abstract}

This paper provides an overview of the process and tools we have developed for assessing the impact of writing development projects carried out in a wide variety of courses at the University of Toronto's Mississauga campus. It begins with an overview of writing studies in Canada to provide a context to our approach to writing instruction and writing program assessment. It then offers a case study of a specific writing development project in a large first-year humanities course, a detailed explanation of the methods we used to measure the efficacy of that project, and an exposition of the way in which this assessment was used to drive reflection on the project and enhancement of it. The paper concludes with summary of the lessons we have learned regarding writing program assessment that navigates between creating a standardized process and responding to the unique needs of multiple projects, as well as a discussion of the benefits of such assessment for writing pedagogy research.

\section{Introduction}

In this paper, we discuss the development of a process for assessing the efficacy of writing projects carried out in a wide variety of courses across the disciplines at the Mississauga campus of University of Toronto (UTM). To provide the reader with an understanding of the context from which our work emerges, particularly with regard to its uniquely Canadian aspects, we begin with an overview of the 
Volume 29, 2019

http://journals.sfu.ca/cjsdw

curricular history of writing studies in Canada to explain how and why UTM employs the "partnership between WI and disciplinary instructor" model of WAC.

Following this, we present a description of the approach to WAC taken at UTM, and explain our assessment methods, highlighting the strategies we use to overcome the challenge of measuring the impact of a remarkable range and diversity of interventions employed by the instructors participating in our WAC program. To demonstrate how we are attempting to meet these assessment challenges, we present one case study of a writing project and its assessment in a large, first-year humanities course. Finally, we conclude with a presentation of some lessons learned and our future directions.

\section{A (Very) Brief History of Writing Instruction in Canada}

In order for readers to appreciate both our approach to writing instruction and our efforts to assess the impact of that instruction, it is important that they understand some of the historic forces that have informed the design of our programming. In their "Introduction" to a collection of essays on Canadian writing pedagogy, Graves and Graves note that the "tradition of writing instruction in Canadian universities offers administrative structures, program design, and pedagogical features that constitute interesting alternative approaches to the traditional first year writing programs established at most American universities" (2006, p. 2). As most Writing Instructors in Canada know, these "alternative approaches" commonly include instruction embedded into existing courses or offered through co-curricular programming at university writing centres. Indeed, writing centres are often responsible for the design and delivery of much of the writing instruction offered on Canadian university campuses, whether it is offered through face-to-face appointments, workshops, online resources, or a WAC program. While writing centres' services and programs certainly have common features from institution to institution, they are also characterized by a tremendous amount of diversity, as Graves and Graves acknowledge through their use of the plural "alternative approaches." Indeed, there are probably as many differences among Canadian universities' strategies for teaching academic writing as there are similarities: in the words of the classic cliché, Canada is a "mosaic" to the United States' "melting pot."

So, how did this happen? How did the field of writing studies in Canada come to be so fragmented? The few published studies of writing instruction at Canadian universities agree that, unlike the more inter-disciplinary, utilitarian approach to composition south of the border, writing instruction in Canada has historically been deeply indebted to the $19^{\text {th }}$ century "belles lettres" tradition in Britain 
Volume 29, 2019

http://journals.sfu.ca/cjsdw

(Graves, 1994; Hubert, 1994 and 1994b; Brooks, 2002; Johnson, 2006; Graves \& Graves, 2006; Kearns \& Turner, 2008). Thus, prior to the relatively recent advent of university writing centres in the 1990s, responsibility for the teaching of writing in Canada had fallen to Departments of English who, over the years, shifted their emphasis in instruction from a focus on text production to text reception (Kearns \& Turner, 2008). Through the $19^{\text {th }}$ and early part of the $20^{\text {th }}$ centuries, the writing curriculum evolved from the study of how to create "elegance" and "propriety" in speech and writing to how to appreciate the masterpieces of English literature which, according to public intellectuals like Matthew Arnold offered "a way of training the mind, and a means of transmitting culture" (Kearns \& Turner, 2008, p. 4). By the turn of the $20^{\text {th }}$ century, students were not being taught writing skills so much as they were being exposed to what Arnold famously referred to as 'the best which has been thought and said'; and, by the middle of the $20^{\text {th }}$ century, rhetoric had effectively been replaced by the study of literature in the curriculum. The ultimate effect of this was, as Hubert and Garrett-Petts observe, decades of writing instruction in Canada characterized by "an agonizingly extended effort" on the part of English Departments "to teach reading without writing" (2006, p. 62).

Things have changed, however, in the last few decades. Writing in 2006, Smith notes that the "traditional literature-focused English department once played a defining role in forming the landscape of writing instruction, but for the past five to ten years it has not played a central role" (p. 324). Indeed, unlike American English departments that have "strengthened their departmental status through academic and professional writing” (p. 324), English departments in Canada have resisted "engaging in the teaching of writing, especially academic writing that might evolve into service teaching for other departments" (Graves and Graves, 2006, p.8). In short, "composition" has never had an opportunity to grow as an independent field of study in Canada; instead, it has been marginalized within English departments who have never acknowledged it as a legitimate area of research and instruction. And so, today the most "distinctive feature of the Canadian context...is that a significant proportion of Canadian writing instruction...[is now] carried out in a variety of disciplinary settings outside of first-year English courses, and indeed often outside of English departments" (Smith, 2006, p. 320). In other words, responsibility for writing instruction at Canadian universities shifted from English departments to writing centres and WAC programs, neither of which is typically located in an academic unit that has formal departmental status. This is precisely the situation at UTM where the writing centre is formally located in the Dean's Office and does not currently have anything like a departmental status. 
Volume 29, 2019

http://journals.sfu.ca/cjsdw

This relocation of writing instruction from English Departments to writing centres may have been a common trend in Canadian postsecondary institutions towards the end of the $20^{\text {th }}$ century, but it certainly did not produce a common result with regards to teaching practices. As Graves and Graves (2006) note, with writing centres serving as the primary site of writing instruction in Canada, the field of writing studies has become characterized by the "lack of structure to allow writing instructors to interact, the relative lack of nationwide organizations to educate and promote the teaching of writing, and the general scarcity of graduate programs to train individuals" (p. 11). In this way, writing instruction in Canadian universities has come to be "characterized by isolated and uncoordinated initiatives, sometimes brilliantly creative and sometimes slavishly imitative; in any case, varying wildly from context to context" (Hunt, 2006, p. 371). And because it seems to fit "nowhere else in the traditional departmental and administrative structure of the universities" writing instruction "has simply infiltrated the cracks, finding housing in administrative units, other departments, writing centres, various ad hoc creations of deans and provosts" (p. 377). Not surprisingly, then, writing studies in Canada has evolved into a collection of novel approaches to a common concern.

This history has had a profound impact on the current state of writing instruction in Canada in a number of different ways. Because "Canadian composition does not share a unified site of research, inquiry, and teacher training like the 'first-year writing course'" (Smith, 2006, p. 320-321) in the United States, writing instructors in Canada have relatively few resources upon which to draw for their programming initiatives. Most critically, there is no pool of trained, experienced instructors and TAs who can teach some variant of a first-year composition course in Canada. Nor is there a large, vibrant professional association, a composition publishing industry, or graduate programs supported by first-year composition programs. In short, because writing studies exists in the "cracks" of our post-secondary institutions, very little scholarship has been dedicated to developing made-in-Canada WAC/WID programming, writing centre pedagogy, or alternatives to (or appropriate versions of) first-year composition.

On the other hand, Graves and Graves (2006), Smith (2006), and Procter (2011) all see potential in the WAC programs that have grown in the interstices separating and connecting academic departments. Graves and Graves (2006), for example, insist that such a positioning leaves "the scope for teaching writing fairly wide open to other sources of instruction, including the writing centres approach" (p. 8). Smith makes a similar point, arguing that the "lack of an established 'centre' for writing instruction and scholarship...means that the small number of Canadian scholars in the field 
Volume 29, 2019

http://journals.sfu.ca/cjsdw

of writing instruction cannot isolate themselves in only one branch of composition scholarship nor, for that matter, a single discipline such as English studies" (p. 321). In other words, the decentralized position of writing studies in Canada has generated a uniquely interdisciplinary field replete with "fresh ideas on how to teach various types of academic and professional writing" (p. 322). According to Margaret Procter, one of the more effective sources of "fresh ideas" on how to teach writing is the university writing centre:

...writing centres have helped create a distinctive position for Writing Studies in the Canadian university culture, one that does not necessarily depend on a departmental home. They can raise awareness of writing issues precisely because to sustain themselves as non-departmental units, they need to argue publicly about the nature of writing as an intellectual activity and to show how their writing instruction across the curriculum contributes to the knowledge creation that is the core value of the university...Writing centre instructors know from daily engagement with students how the process of writing generates and shapes ideas, rather than simply transmitting or packaging them. (p. 416)

This is precisely the situation with the writing centre at UTM. The lack of a departmental home has forced it to develop unique strategies for teaching writing, many of which have required partnerships with disciplinary faculty across the curriculum. These partnerships have in turn created a community of scholars on campus who believe that, as Procter says, writing instruction is a key component of the knowledge creation process. Our WAC program at UTM is funded by the Office of the Dean, administered by the writing centre, and delivered through dozens of different partnerships between writing centre instructors and disciplinary faculty. Many of the interventions rely on talented teaching assistants who receive many hours of training on how to provide effective feedback, deliver in-class workshops, or provide other kinds of writing support. In short, we should probably say that the program is, in fact, many different projects, each tailored to the unique needs of the disciplinary instructor with whom the writing centre is partnering in that particular year. These are all immensely positive aspects of our program, but they involve responsibilities on our part: for one thing, there is no escaping the importance of assessment to justify our support, improve our teaching, and put this writing community on a solid footing; for another, this diversity means that we cannot rely on a standardized form of assessment.

In the rest of this article, we discuss the compromise that we have developed to respond to these needs, namely the Basic Assessment Package (BAP); first, however, we move from speaking generally about the nature of Canadian writing instruction to speaking specifically about our project at UTM. 
Volume 29, 2019

http://journals.sfu.ca/cjsdw

\section{The Writing Development Initiative: A Case Study}

The combination of writing specialists and disciplinary faculty to design and/or deliver and/or assess writing projects is logical: disciplinary faculty bring their knowledge of the field and the needs of their students at the various levels, and they also bring in-depth knowledge of the program, its expectations, and the way its various component courses fit together. Writing specialists, for their part, bring their expertise in teaching writing and teaching through writing, as well as a knowledge of current research in Writing Studies and, quite possibly, the campus history of writing instruction. In other words, involving writing specialists brings in not just pedagogical expertise, but also a sense of context to the project. When writing specialists provide this kind of support for a wide variety of faculty members across the curriculum, as has been the case at UTM, a need for a more formal system of organizing these collaborations emerges. And in fact, one way of providing consistent writing support to a large number of faculty members in a variety of disciplines while remaining responsive to disciplinary needs is to set up an institutional structure, with attached expertise, for support, but to allow disciplinary experts to take the lead in designing and implementing the pedagogical intervention. The Writing Development Initiative (WDI) at UTM is an example of just such a structure.

Situated about $30 \mathrm{~km}$ to the west of University of Toronto's main campus, UTM was established in 1967 and is the second-largest division of the University of Toronto, one of Canada's largest public research universities. In 2017 when this research was conducted, UTM included 13,963 undergraduate students, 740 graduate students, and approximately 1,100 permanent faculty and staff. While approximately 3,000 (21\%) of the undergraduate student population paid international student fees in 2017, a significantly higher proportion of the student body does not speak English as a first language and so could be considered English Language Learners (ELL). The English language requirement is four or more years of full-time study at an English language high school or a minimum score on a recognized test of English facility such as the TOEFL. As with most Canadian universities, UTM does not require students to write a post-admission English proficiency test and does not offer a First-Year Composition (FYC) course.

The WDI was created in 2004: for the past fifteen years, it has been supporting innovative projects for incorporating additional use of writing into core courses, or courses that are at significant junctures in their programs-thus the WDI supports projects focusing on basic disciplinary skills in many large introductory first-year courses, but also projects such as the one in a core second-year Psychology course, which is explicitly designed to prepare Psychology students for the writing 
Volume 29, 2019

http://journals.sfu.ca/cjsdw

challenges they will face in third year, or the one in a third-year Earth Sciences course that focuses on developing research grant proposals, giving students experience that they will need as they start planning life beyond undergraduate studies.

The WDI supports projects in courses from across the disciplines. In 2017/2018, the year under discussion in this article, it supported projects in 30 courses from the following Departments: Biology; Chemical and Physical Science; Communication, Culture, Information and Technology; Economics; English; Geography (including Environmental Sciences); Historical Studies (at UTM this includes Religious Studies); Linguistics; Mathematics and Computer Sciences; Political Science; Psychology; Sociology; and Visual Studies. All but one of these ran in the Fall/Winter session; there was one course that ran in summer 2018.

The WDI's process requires that disciplinary faculty take the lead in proposing and developing these projects: they identify the most pressing needs of their students and come up with a plan for addressing these needs, often consulting with faculty at the Robert Gillespie Academic Skills Centre (RGASC) in the process. For instance, in the Psychology course mentioned above, the instructor was inspired to create his project, which involves the critical analysis of the use of science in a popular media article, because he noticed that students were unprepared for the increased focus on critical writing and reading in upper-year courses.

The RGASC circulates a Call for Proposals in February of each year, and its Writing Specialist is available to work with interested faculty as they develop their plans for submission. The process is adjudicated by a Committee, which includes representatives of Humanities, Sciences, and Social Sciences, as well as the Library and the RGASC. The Committee meets twice. The first time, in April, it considers new proposals, either accepting them, rejecting them, or requesting revisions; the second time, in early June, it considers revised new proposals as well as already-existing projects, basing its adjudications for the latter on the Final Reports that every project is required to submit and a discussion of the efficacy of the project and its proposed changes.

The WDI has steadily built up its organizational ambitions and processes, moving from its quite informal beginnings to its present well-defined and coherent structure. Its most significant development in recent years has been a heightened emphasis on the assessment of the impact of individual writing projects; the data collection and analysis conducted as part of the assessment process is not conducted by individual faculty members. Instead, it is coordinated by the RGASC, which hires Research Assistants with funding provided by the Office of the Dean as part of its commitment to assess and review all academic programs on an ongoing basis. 
Volume 29, 2019

http://journals.sfu.ca/cjsdw

\section{Focus on Assessment}

Assessment-whether for writing centres or for the work that they support-is crucial. As Isabelle Thompson (2006) clearly pointed out more than a decade ago in an article on the need for writing centres to self-assess, it is a professional obligation for those of us who work in writing centres: it makes our work visible to others and legitimates us; it drives research; and it encourages reflection, which in turn enhances our work.

However, assessment of the development of written communication skills is undeniably difficult to do. While many of the best practices for assessing the impact of writing instruction are welldocumented (e.g., O’Neill, Moore \& Huot, 2009; Yancey \& Huot, 1999; Elliot \& Perelman, 2012), scholars in the field acknowledge that the assessment of writing programs remains an inexact science. Factors that prevent such assessment from yielding precise results include the following: students are rarely taking just one course (and so we cannot isolate the sources of their learning); students' writing practices are impacted by a wide variety of (academic and non-academic) variables; learning takes time to sink in and gains might not be apparent in a mere four (or eight) months; and the course is not a lab in which ideal conditions for writing research can be set up.

Assessment is especially difficult in WAC/WID programs with distinct, idiosyncratic, genresensitive projects tightly linked to and responding to authentic learning situations in a unique institutional program of studies. Such projects are typically, as Fulwiler (1988) put it many years ago, "faculty centred": they "identify the instructors of a given institution as...the primary agents of instruction [and] the determiners of writing assignments, including the nature, purpose, frequency, and kind of writing asked for." These are precisely the sorts of projects that one wants to encourage, but their very nature rules out simple or one-size-fits-all approaches to assessment—or, as Pruchnic et al (2018) put it, "the problematic decontextualization of program goals and student achievement." The influential "Statement of WAC Principles and Practices" (2014) endorsed by both the International Network of Writing-across-the-Curriculum Programs (INWAC) and the Conference on College Composition and Communication's Executive Committee makes a similar point about decontextualization as it relates to assessment, arguing that "at the course level, then, good writing assessment attends to specific, situated, and articulated assignment and course learning goals for students" (INWAC). Similarly, the Conference on College Communication and Composition's (CCCC) "Writing Assessment: A Position Statement" stresses that "the methods and criteria that readers use 
Volume 29, 2019

http://journals.sfu.ca/cjsdw

to assess writing should be locally developed, deriving from the particular context and purposes for the writing being assessed" (CCCC).

Not only is writing program assessment difficult because of the inability to develop generalizable methods and tools, but it is also undeniably labour intensive, requiring an investment of time and energy from all collaborators and also requiring some knowledge of appropriate research methods to be done well. For the instructor, planning and executing the assessment of course also represents a competing demand that needs to be juggled with all the other course-related demands on her time.

\section{Methods of Assessment}

For these reasons, it should not be surprising that the efficacy of writing projects is very often assessed simply through the use of student surveys or through analysis of student marks on assignments. Faculty members with projects supported by the WDI must submit a Final Report at the end of the year, in which they discuss (among other things) the efficacy of their writing project: to demonstrate this efficacy, faculty have historically used a fairly wide variety of approaches, (see Table 1 below), many of which were created for or arise out of specific aspects of the courses in which they were deployed. While this wide variety of approaches and instruments has been used in the years leading up to the BAP, most of the assessment data have actually been collected through a) general, end of term student surveys; b) grades on assignments; and c) anecdotal reports from instructors or TAs. The apparent preference for these assessment tools on the part of instructors inspired our thinking about a more coherent assessment model that would be broadly applicable to the diverse courses participating in the WDI. 
Volume 29, 2019

http://journals.sfu.ca/cjsdw

Table 1. Methods of Assessment: Pre-BAP (2004-2017)

\begin{tabular}{|l|}
\hline Exit interviews with TAs \\
\hline Discussion with TAs during term \\
\hline Instructor's reflections on the impact of interventions \\
\hline Presentation of changes to course, tutorial content, assignments \\
\hline Mid-term review of course by instructor and RGASC member \\
\hline Student evaluations without writing-specific questions \\
\hline Student evaluations or surveys with writing-specific questions \\
\hline Pre- and post-test writing tasks \\
\hline Online grammar quizzes \\
\hline Discourse analysis \\
\hline In-class or in-tutorial tests focused on writing skills \\
\hline Examination of low-/no-stakes writing exercises \\
\hline Student performance on WDI-supported writing assignments \\
\hline Comparison of grades or specific aspects of various submissions \\
\hline Changes to and student comments on revision assignments \\
\hline Changes from draft to final versions of written submissions \\
\hline Comparison of assignments from different years \\
\hline Marks differences year to year \\
\hline Rate of change in academic integrity issues year to year \\
\hline Retention rate changes year to year \\
\hline
\end{tabular}

The BAP is our solution to the problem of balancing course- and project-specific aspects with a standardized format: like the most popular data collections deployed thus far, it uses student surveys (but presents them at the start and end of term and has them target specific learning outcomes of the project); it draws on writing assignments (but analyzes them based on how they show development towards specific learning outcomes); and it collects the feedback from teaching staff (but in the form of a formal, tailored survey).

\section{The Basic Assessment Program}

Our concerns with regard to assessment of WDI projects can be separated into three types: administratively, we assess so as to ensure that we are being good stewards of the WDI resources and that the project fits in its course and develops skills that are appropriate to that stage of its program; collegially, we use assessment as a means of building up a writing community at UTM; pedagogically, we use assessment as a means of enhancing the projects by obliging instructors to engage reflectively with them, to think about what is working and what is not working, and to revise their projects based on this. To do this assessment, we have developed a Basic Assessment Package 
Volume 29, 2019

http://journals.sfu.ca/cjsdw

(BAP), which in our view enables us to address these concerns in a manner that is both acceptably rigorous and doable.

The assessment process for the WDI works as follows: In the summer (or November for winter courses), the WDI Coordinator meets with the instructor from each of the courses supported by the WDI (30 courses for 2017/2018) to discuss both their project and its assessment. While instructors are free to propose their own methods for assessing their projects, in the vast majority of cases the Coordinator and instructor agree to use the BAP, which consists of the following elements:

a) Anonymous student surveys (administered online through SurveyMonkey) asking about students' perceptions of the writing project and/or its goals.

b) End-of-term interviews with TAs, or questionnaires sent out to TAs, again focused on their perceptions of the impact of the writing project.

c) Analysis of student writing samples: the selection, anonymizing, and analyses are done by the WDI Coordinator or Research Assistants hired by the RGASC, not course TAs or the instructor; the instructor receives the results of the analyses, but not the raw data (i.e., student writing samples or rubrics).

If, as is usually the case, the instructor wishes to have the BAP run in her course rather than design her own assessment process, the RGASC creates rubrics and surveys for each project being assessed. These are meant to respond to the specific goals and learning objectives (LOs) of the WDI project, which are determined through a two-stage process. First, the WDI coordinator reads through the project's WDI proposal, its annual Final Reports (if applicable), and course materials (e.g., course outline and assignments), in order to determine the instructor's priorities-sometimes sleuth work is required, as the instructor may not have clearly expressed or even conceptualized her priorities in these documents.

After having done this sleuthing, the reconstructed goals and LOs for the project are confirmed or adjusted through discussion with the instructor and are used to construct the surveys and rubrics for analysing writing samples. Some instructors' goals for a given project-such as increasing students' feeling of self-efficacy or comfort with writing-are more appropriately measured through surveys, while others - such as developing students' abilities to generate and structure arguments-are more appropriately measured through writing analyses. It is important to note that due to the projectspecific focus of this assessment project, these surveys are different from regular student evaluation surveys, and rubrics used for writing sample analyses are usually significantly different from rubrics used by course TAs to grade assignments. 
Volume 29, 2019

http://journals.sfu.ca/cjsdw

\section{The Goals of the BAP}

The above caveats lead into our next, and key, point: As writing instructors, we are deeply interested in all facets of student writing, but in the context of this assessment project our concerns are necessarily more limited, in that we want to ensure that we are measuring the degree to which the goals of the funded writing proj; ect are achieved (although this information can of course be put to wide use, extending from the instructor's own reflection on and adjustment of the project outward to applications for SoTL and writing pedagogy research). In other words, if the project is designed to focus exclusively on sentence-level issues, then that is what we focus on too in our analysis of student writing samples, even if this is only a small part of the concerns of the course TA who is grading the assignment. In this assessment project, we are not learning generally about what helps make students better writers; instead, we are learning about the impact of a specific intervention on specific kinds of students working in specific contexts. It is one of the strengths of the BAP that it emphasizes this distinction between the instructor's broader goals and the course's overall LOs, on the one hand, and the instructor's project-specific goals and LOs on the other.

\section{The BAP in a Large First-Year Humanities course}

To give a concrete example of how the BAP works, we will draw on our work with HUM1XX, a large (ca. 400 students) introductory humanities course. The main objective of the WDI funding in this course was to add a revision stage to the first paper, so that students would be obliged to read and integrate TA feedback, in the hope that this would assist them in developing their own self-editing skills.

The writing assignments are described in the course outline as follows:

a) A first paper, ca. 2 pages, in which students write a detailed description of a scene from a movie (movie chosen by the instructor) and make an argument about the effect of the arrangement of elements in the scene. This paper is due in early October, and is returned with TA comments by mid-October, allowing students to produce ...

b) A revision of the first paper, due early November, incorporating the TA feedback.

c) A second paper, ca. 4-6 pages, in which students write a detailed analysis of 2-3 scenes from a movie of their choice and make an argument about the effect of the arrangement of elements in the scene. This paper was due at the start of December. 
Volume 29, 2019

http://journals.sfu.ca/cjsdw

Step 2, the revision of the first paper, was funded entirely by the WDI; thus, it is clear that the WDI's emphasis has to do with responding to feedback and editing skills. Some of the feedback that students were responding to had to do specifically with sentence level issues, but more of it had to do with creating an argument, presenting that argument coherently, and using evidence to support that argument.

\section{Establishing Focuses for the BAP}

The WDI funded projects in three first-year courses in this single Humanities Department; although the projects were all different, they shared a concern with sentence-level writing issues. For the course currently under discussion, the Final Report that had been submitted to the WDI Committee the previous year identified a main goal of the project as helping students develop their self-editing abilities. In planning meetings with the Writing Specialist, the course instructor indicated that they wanted TAs to focus on students' grammar and argument structure when providing feedback and teaching tutorials; the instructor also identified their own overall goals for the project as being to enhance students' editing abilities and critical faculties, as well as students' confidence in their own writing skills. Thus the instructor's hope was that by obliging students to deal seriously with TA feedback, they would contribute to the development of the students' own, transferable editing and revision skills.

All TAs had been given the opportunity to attend a 7-hour WDI Writing TA Training program, of which several of the modules addressed issues directly relevant to the course instructor's concernsthese include modules on best practices for feedback, giving feedback on sentence level issues, and working with ELL students. The WDI Writing TA Training program is not specific to any one course, however, and no course- or assignment-specific TA training was requested by the instructor. 
Volume 29, 2019

http://journals.sfu.ca/cjsdw

Course TAs were already assessing the changes, directly prompted by TA feedback, that students made from Paper One to the revision of Paper One. For this reason, we chose to sample from Paper One and Paper Two to assess what changes were made when they were not directly prompted, so as to determine the transferable learning that arose from their work with the TAs' feedback. In discussion with the course instructor, four broad categories for analysis were established (detailed breakdown below):

- Interpretation

- Use of Evidence

- Organization

- Language

\section{BAP Methodology}

Research Ethics approval for this project was not sought, as the student writing would not be used externally. To arrange for writing samples, we introduced the project in an early class (midSeptember 2017) and distributed an Informed Consent letter. Students were invited to sign and date the form if they gave permission for their writing to form part of the sample pool.

In total, 171 students (ca. $43 \%$ of the total number of students enrolled) submitted filled in IC forms. Subsequently, 40 of them were randomly chosen (10\% of class total) by a WDI Research Assistant (RA) unconnected to the course; samples of their writing were anonymized and then sent to a different RA, along with rubrics, to be analyzed. The RA was asked to assess the writing samples following the rubric, and also to provide a ca. 1-page discussion of patterns or noteworthy features that they had observed in the writing samples. Writing samples were graded according to rubric elements on a scale from 1-5, with 1 indicating that the criterion was entirely absent or done but unacceptably so, 2.5-3 indicating that it was acceptably done, and 5 indicating that it was completely fulfilled.

With regard to writing support for the course, the RGASC's Writing Specialist facilitated a workshop on thesis statements in the course one week before the deadline for Paper Two, stressing the importance of the thesis as a guide to the paper as a whole and helping students to understand thesis-driven papers as coherently organized, argumentative works. This workshop thus supports the LOs associated with the WDI project, but was not conceived of by the instructor as being directly tied into the WDI project; rather, it was the sort of workshop that the RGASC provides for a wide variety of courses. We also organized four "dedicated drop-in sessions" during the term when 
Volume 29, 2019

http://journals.sfu.ca/cjsdw

students in the course could come to the RGASC and work with the Writing Specialist on their essays: 24 students attended these drop-ins.

Student views were gathered through anonymous pre- and post- surveys that were created and posted on SurveyMonkey and promoted on the course website. There were 68 responses to the presurvey, and 40 to the post-: as these were anonymous, we do not know if the students whose writing was analyzed were among the respondents. TA interviews were recorded in December 2017 in a group interview with the RGASC's Writing Specialist, then transcribed by a WDI RA. TAs were informed that the interview would not be anonymous.

The data-writing sample analyses, the RA's overview of the changes in writing in the course, student survey responses, and a transcript of the TA interview-were sent to the course instructor in April 2018, so that they could make use of it in preparing their Final Report on the project in $2017 / 2018$. As will be seen below, the instructor did indeed make use of it, in both summative and formative senses.

In what follows, we present the tools that we created for the assessment process for this course. The three sources of data-writing analyses, student responses to surveys, TA interviews or (in some cases) responses to questionnaires-were the same for almost all the BAPs, regardless of course: the specific content for the first two was based on the course's unique project and hence unique assessment needs. The same TA interview scripts or questionnaires were used for all courses, although in interviews discussion would get more course-specific.

\section{BAP Data Collection Instruments}

The WDI proposal, our subsequent discussion with course instructor, and our understanding of the overall concerns for the three WDI-supported courses in the department enabled us to develop the following data collection instruments, whose foci were tailored to respond to the learning objectives and concerns that we had identified.

Student Writing Samples. Table 2 provides an overview of the criteria we used to analyze students' writing, emphasizing organization and language (the latter being a particular concern of the department, the former being of specific concern in the context of the course). 
Volume 29, 2019

http://journals.sfu.ca/cjsdw

Table 2. Assessment Criteria for Analyzing Student Writing Samples

\begin{tabular}{|l|l|}
\hline Category & Assessment Criteria \\
\hline Interpretation & There is a recognizable thesis that makes a claim \\
\hline Evidence & Points made are supported by the presentation of evidence \\
\hline Organization & The paper is coherently organized \\
\hline & $\begin{array}{l}\text { The reader is guided through the paper's argument by effective use of } \\
\text { signposting, transition words, etc. }\end{array}$ \\
\hline & The paper is divided into paragraphs organized around a main idea \\
\hline Language & Paragraph focuses are exposed through topic sentences \\
\hline & $\begin{array}{l}\text { Sentence structures are clear and easy to understand } \\
\text { with reader comprehension }\end{array}$ \\
\hline & $\begin{array}{l}\text { The writing is academic in tone (i.e., no verb contractions, slang, colloquialisms, } \\
\text { etc.) }\end{array}$ \\
\hline
\end{tabular}

The data from the analyses were also accompanied by a 1-page summary prepared by a research assistant giving an overview and pointing out elements that they felt were significant but that might not show up strictly in the rubrics.

Student Surveys. Because the instructor's specific learning objectives for the course were to enhance students' confidence and ability to edit, we designed student surveys to assess students' perceptions of changes in their sense of self-efficacy as writers and their writing process more generally; the goal of these questions was to get a sense of the degree to which the course's emphasis on revision and editing had affected students' practice, or at least their perceptions of their practice. The questions thus are intended to measure students' self-understanding and changes in that selfunderstanding, rather than assessing their work. Table 3 contains the questions included on both the Pre- and Post-Surveys.

TA Interviews. The RGASC's Writing Specialist conducted an hour-long, paid group interview with the course's TAs, asking about the efficacy of the writing project, as well as its impact on them. Table 4 comprises the questions that formed the interview script we designed to assess TAs' perceptions of the impact of the WDI on both the students in the course and their own professional development. The same script has been used in TA interviews for all the courses supported by the WDI and thus has not been specific to any one course, although TA answers are: the logic behind this approach was that the WDI's RAs would cover the WDI-specific assessment of the students' work, and could do this from a more distanced viewpoint than course TAs. The questions in the script thus draw out a perspective that only course TAs can provide; they also address the benefits of being 
Volume 29, 2019

http://journals.sfu.ca/cjsdw

involved in this project for TAs, as supporting their professional development and their work with writing is part of our mandate.

Table 3. BAP Survey Questions

\begin{tabular}{|c|c|c|}
\hline Writing Outcome & Question & Rating Scale \\
\hline \multirow[t]{7}{*}{$\begin{array}{l}\text { Students' Writing } \\
\text { Confidence }\end{array}$} & $\begin{array}{l}\text { How would you rate your academic } \\
\text { writing skills? }\end{array}$ & $\begin{array}{l}\text { Excellent, strong, okay, weak, } \\
\text { very weak }\end{array}$ \\
\hline & $\begin{array}{l}\text { University courses usually involve a lot of } \\
\text { writing. How worried are you about this? }\end{array}$ & $\begin{array}{l}\text { Very worried, somewhat } \\
\text { worried, a little worried, not } \\
\text { very worried, not worried at } \\
\text { all }\end{array}$ \\
\hline & $\begin{array}{l}\text { University courses typically expect you to } \\
\text { come up with your own arguments based } \\
\text { on your reading or observations. How } \\
\text { would you rate your ability to do this? }\end{array}$ & $\begin{array}{l}\text { Excellent, strong, competent, } \\
\text { weak, very weak }\end{array}$ \\
\hline & $\begin{array}{l}\text { How would you rate your ability to } \\
\text { organize your papers so that they make } \\
\text { sense and are convincing? }\end{array}$ & $\begin{array}{l}\text { Excellent, strong, competent, } \\
\text { weak, very weak }\end{array}$ \\
\hline & $\begin{array}{l}\text { How would you rate your ability to } \\
\text { accurately quote, paraphrase, or } \\
\text { summarize information that you read? }\end{array}$ & $\begin{array}{l}\text { Excellent, strong, competent, } \\
\text { weak, very weak }\end{array}$ \\
\hline & $\begin{array}{l}\text { How would you rate your abilities to write } \\
\text { grammatically correct sentences }\end{array}$ & $\begin{array}{l}\text { Excellent, strong, competent, } \\
\text { weak, very weak }\end{array}$ \\
\hline & $\begin{array}{l}\text { How would you rate your abilities to write } \\
\text { clear, well-organized sentences? }\end{array}$ & $\begin{array}{l}\text { Excellent, strong, competent, } \\
\text { weak, very weak }\end{array}$ \\
\hline \multirow{4}{*}{$\begin{array}{l}\text { Students' } \\
\text { Approach to the } \\
\text { Writing Process }\end{array}$} & Do you write outlines for your papers? & $\begin{array}{l}\text { Always, most of the time, } \\
\text { sometimes, rarely, never }\end{array}$ \\
\hline & $\begin{array}{l}\text { How far in advance of the deadline do you } \\
\text { start working on your writing } \\
\text { assignments? }\end{array}$ & $\begin{array}{l}\text { A month or more; a few } \\
\text { weeks; a week; several days; I } \\
\text { do them at the last minute }\end{array}$ \\
\hline & $\begin{array}{l}\text { How many drafts of a paper do you } \\
\text { typically write? }\end{array}$ & $\begin{array}{l}\text { More than four, four, three, } \\
\text { two, one }\end{array}$ \\
\hline & $\begin{array}{l}\text { When you write something for school, how } \\
\text { much time do you spend editing it-i.e., } \\
\text { checking to make sure that sentences and } \\
\text { paragraphs are clearly and correctly } \\
\text { written? }\end{array}$ & $\begin{array}{l}\text { I go through it line by line, I } \\
\text { read it over once or twice, I } \\
\text { look it over and make } \\
\text { whatever changes seem } \\
\text { necessary, I don't usually edit }\end{array}$ \\
\hline
\end{tabular}


Volume 29, 2019

http://journals.sfu.ca/cjsdw

Table 4. Interview Questions for Teaching Assistants

\begin{tabular}{|c|c|}
\hline With regard to & Please describe the project as you understand it. \\
\hline & What were your responsibilities with regard to this project? \\
\hline & What kind of related experience have you had? \\
\hline & $\begin{array}{l}\text { What training/support did you get from the RGASC or the } \\
\text { instructor? }\end{array}$ \\
\hline & Was the training or support adequate? \\
\hline & If not, how could it have been improved? \\
\hline \multirow{7}{*}{$\begin{array}{l}\text { With regard to the } \\
\text { project's effects on } \\
\text { students }\end{array}$} & $\begin{array}{l}\text { What feedback did you get from students about the project's } \\
\text { components? }\end{array}$ \\
\hline & $\begin{array}{l}\text { Overall, how do you think that students felt about the project, and } \\
\text { why do you think this? }\end{array}$ \\
\hline & $\begin{array}{l}\text { What effects do you think this project had on the students' general } \\
\text { writing abilities, and how did it help to produce these effects? }\end{array}$ \\
\hline & $\begin{array}{l}\text { On their critical thinking and critical writing abilities, and how did it } \\
\text { help produce these effects? }\end{array}$ \\
\hline & $\begin{array}{l}\text { On their abilities to think and communicate in discipline- } \\
\text { appropriate ways, and how did it help to produce these effects? Did } \\
\text { the project interfere with your ability to address course content? }\end{array}$ \\
\hline & $\begin{array}{l}\text { Was there a difference in the project's impact on ELL and non-ELL } \\
\text { students? If so, please explain. }\end{array}$ \\
\hline & $\begin{array}{l}\text { Do you have any suggestions as to how the project could be changed } \\
\text { or improved? }\end{array}$ \\
\hline \multirow{5}{*}{$\begin{array}{l}\text { With regard to the } \\
\text { benefits and challenges } \\
\text { for them of having been } \\
\text { involved }\end{array}$} & What were the most challenging parts of the project for you? \\
\hline & What were the most rewarding parts of the project for you? \\
\hline & $\begin{array}{l}\text { In what ways has being involved in this project enhanced your } \\
\text { professional development as TAs and future or current instructors? }\end{array}$ \\
\hline & $\begin{array}{l}\text { Has being involved in this project affected how you approach your } \\
\text { own work or writing? }\end{array}$ \\
\hline & $\begin{array}{l}\text { What elements of this project will you be likely to draw on in your } \\
\text { future career? }\end{array}$ \\
\hline Open-Ended & $\begin{array}{l}\text { Do you have any further comments or details about the project that } \\
\text { you would like to share? }\end{array}$ \\
\hline
\end{tabular}


Volume 29, 2019

http://journals.sfu.ca/cjsdw

Instructor's Use of the BAP

In the Final Report for the course, the instructor drew frequently on the BAP, both as summative information and also as formative material for rethinking both aspects of TA training and the nature of the two main writing assignments. For instance, he drew on BAP survey data, integrated with his own course evaluations, to demonstrate that students overall felt that the course's project had helped them improve their writing abilities and comfort with writing; most significantly, he noted a steep drop in the number of students who said that they were "very worried" about their writing abilities in the BAP surveys, and combined this with noting appreciations for the writing support in the course evaluations. He drew on the TA interview data in particular to bring out the need for more TA training in offering useful feedback to ELL students, of which the course has many, and requested extra funding from the WDI to offer enhanced TA training focusing on this (this training to be designed by the XXASC Writing Specialist). This interview data also alerted him to the fact that TAs felt that students were less invested in the first paper than in the second (since they were allowed to choose their own film and scenes to analyze in the second); he used this observation to guide his interpretation of the writing analysis data. This in turn led him to reconsider the revision phase of the first paper, proposing instead to bring the revision into the second paper, since students were more invested in it and thus more likely to take the feedback seriously and use it.

In short, the BAP provided this instructor with valuable information about student writing in his class, enhancing his understanding of their project and spurring reflective thinking as he engaged with the BAP and planned his next steps: it gave him tools to help him conceptualize and plan improvements in his teaching. It thus aligns with Huot's call for assessment to provide "critical standard with which communities of knowledgeable stakeholders make important and valid decisions" (1996, p. 558).

\section{Reflections and Future Research}

As we write, we are in the BAP's second year. The data collected through the BAP showed up in most of the Final Reports on WDI projects in the previous year. In some cases, the data were used only in a summative manner, with the instructor speaking retrospectively; in these cases, it ensured that the assessments in Final Reports rested on more solid foundations than would otherwise have been the case: in many cases, instructors used the data-particularly from the writing analyses-to buttress their claims of student improvement in the targeted areas over the course of the term. 
Volume 29, 2019

http://journals.sfu.ca/cjsdw

In several cases, however, the assessment data were used by instructors to engage in more detailed reflection on their courses and writing projects which often resulted in significant revisions, as we saw in the case study above. For instance, in the Final Report for a second-year Psychology course's project, the instructor reflects on his experiences, noting that having access to the BAP materials made him more aware of the challenges of his scaffolded assignment structure both for TAs (in terms of crafting useful feedback for the next stage of the assignment) and students (in terms of understanding and implementing that feedback). This awareness has led him to rethink his project, adding to it more specific training in feedback approaches for course TAs, and creating opportunities for students to work with the feedback and get assessment of their revisions, both of which involving the participation of the RGASC Writing Specialist. Clearly, the assessment data generated by the RGASC has changed this instructor's understanding of the role feedback plays in his students' learning. His participation in the assessment project has inspired him to rethink both the training he provides to TAs and the design of his assignment. Perhaps more importantly, this instructor is committed to an ongoing partnership with a Writing Specialist so that he can continue to use scholarly inquiry to improve his teaching.

This sort of reflective thinking shows that the BAP is already contributing to a culture of teaching and learning on our campus, and we expect that it will do so increasingly as instructors grow accustomed to it. Indeed, several instructors this year have independently proposed ways to customize the BAP so as to make it more responsive to their unique concerns in the course. As Huot (1996) has argued, one of the real benefits of assessment is that it is formative--it drives development and reflection.

As well, the BAP has already contributed to the development of several individual research projects. In one case, it served as a "test run" for larger-scale research project exploring student responses to different kinds of TA feedback in a large first-year humanities course. The instructors of two large second-year science courses are, similarly, using the BAP this year in their courses to develop and pre-test ideas for research projects to be run in future years. A third year social science course has drawn on the experience of working with the WDI and the BAP for a paper and a major conference presentation.

In short, after one year, our assessment project is giving us information on what interventions work and don't work; providing insights that are driving innovation in existing writing projects; and supporting ongoing research into writing pedagogy. 
Volume 29, 2019

http://journals.sfu.ca/cjsdw

\section{Dangers and Lessons Learned}

This is not to say that everything went smoothly this past year. There are several "lessons learned" that might be applicable to others considering running similar projects.

\section{Keep in Touch!}

One major selling point of the BAP for instructors is the fact that they are not doing the data collection and analysis. The WDI coordinator can conduct the assessment without needing to make major demands on them. Despite this, we found that it is crucial to keep in touch with instructors (without pestering them), because "life happens" and projects change unpredictably. In three cases in the BAP's first year (i.e., 12\% of the courses supported by the WDI), exigencies beyond the instructors' control meant that major aspects of the writing project were dramatically altered. In one case, significantly different views of the importance of writing between two instructors in different sections of a course meant that the writing project was not carried out in one section of the course. In another, room booking issues meant that the project had to be completely re-designed (on the fly). In a third case, communication problems between a TA and instructors meant that two-thirds of the project was not carried out. In none of these cases did instructors proactively reach out to us to let us know. In two of the above cases, we found out about the changes while we were planning support for the respective courses and were somewhat able to adjust our planning in consequence; in the third case, however, we did not find out until the Final Report was submitted, and there was therefore no way we could adjust for it.

\section{The Importance of Continuity}

The goal of the WDI is to create opportunities to develop projects that will be run over many years, and that may even become permanent parts of the course ${ }^{1}$. This means that sooner or later, the instructor who created the project will not be teaching the course, whether for a year (as in the case of sabbatical or other leave) or permanently (if the course changes hands). We have found that in some cases instructors will be well-prepared, ensuring that materials and plans are made available to their replacement, and making it clear that the project is an integral part of the course. In other cases, and particularly when sessional instructors are hired to teach, it is necessary to ensure that the department and instructor take responsibility for letting the new/temporary instructor know 
Volume 29, 2019

http://journals.sfu.ca/cjsdw

about the project (ideally including language in the job posting if hiring sessional instructors) and providing them with the appropriate materials (and, if necessary, financial compensation for the additional work they are doing). We can help with this, but we can't take the lead in it.

\section{Submission Format Matters}

Perhaps this will seem obvious, but in terms of student writing samples, and particularly in large classes, hard copy submissions present real logistical challenges in terms of sampling while retaining the anonymity of the students chosen for the sampling. This is not at all to say that hard copy submissions should be automatically avoided: it is easy to think of situations, such as in-class writing work, where they are essential. But it is to say that format needs to be known as far in advance as possible, and taken seriously into consideration in the planning stage.

\section{TAs Are Busy People}

Planning that requires a great deal of input from TAs will often be risky, unless the instructor is completely onboard and pushing hard for you (which we, happily, found to often be the case). This explains why, for instance, we have decided to switch to questionnaires for the end-of-term TA input rather than try to set up group meetings.

\section{It is Difficult to Get Student Participation}

As most of us in the teaching and learning community know, it can be challenging to recruit students to participate in an educational research. As Cyr, Childs, and Elgie (2013) observe, there are a number of factors to take into consideration when inviting students to participate in a research project: "students must know about the study, want to participate, be able to participate and, finally, log in or show up" (p. 4). In some courses, insufficient numbers of students agreed to participate, or the distribution of students was skewed to one end of the grade spectrum, or students agreed to participate in one part of the project (by allowing us to collect writing samples), but did not complete the other component (the survey). The reasons for this are clear. We did not use incentives when recruiting; we made only one appearance in class to describe the research and ask students to sign an Informed Consent form; we did not make an effort to speak to the different motivations students might have for participating; and we did not design sophisticated recruitment tools or use different modes of communication when recruiting (Cyr, Childs, \& Elgie, 2013). We took this approach because 
Volume 29, 2019

http://journals.sfu.ca/cjsdw

we wanted to minimize the disruptive effects our research would have on our colleagues' classes, but we plan to change our recruitment strategies in the future.

\section{Next Steps}

The next year or two will feature several promising developments in our assessment project. One of the most promising, which we referred to above, is the increasing interest that instructors have shown in tweaking the BAP so that it best fits their project: the BAP is becoming a more flexible tool than it was. In our planning work with instructors this year (2018/2019), several instructors have independently proposed changes to the BAP (such as additional sampling stages or additional survey questions or changes to our rubrics) so as to adapt it to the specific goals of their projects. We hope and expect that this increased comfort with the BAP will also lead to greater use of its data in Final Reports at the end of the year.

As well, in order to increase the rigor and the capabilities of the BAP, we will be increasing our sampling to $15 \%$ of the students, up from $10 \%$ this past year; we will also be conducting more rigorous benchmarking with RAs before they assess, and providing them with course syllabi and complete assignment descriptions for the courses whose writing samples they analyze, to help them better understand the context in which the writing was done.

These are opportunities that are being offered to the BAP; in order to make the most use of them, a major consideration will be to enhance the rigor and sophistication of the processes and tools used in the BAP. Since its inception in 2004, the WDI has grown in exactly this fashion, with every expansion in resources being followed by a trial and error process of determining how these resources can be best utilized in our unique context of assessing and supporting a very wide range of small to large writing projects, with an equally wide range of explicit and implicit objectives. After two years (2017/2018 and 2018/2019) of dramatic expansion of assessment, 2019/2020 will be focused on refining our process and tools to enhance our ability to produce valid analyses that respond to instructors' concerns.

We do not, however, foresee this refinement leading in the direction of uniformity or standardization in terms of how we work with student writing. Because the BAP is assessing interventions that employ very different writing pedagogies and that are (at least implicitly) inspired by rather disparate theories of writing, the program cannot collect and analyze data in any one manner. Each project needs to be assessed differently, using tools, methods, and processes that are aligned with the unique goals of the instructor who proposed and executed it. This, of course, 
Volume 29, 2019

http://journals.sfu.ca/cjsdw

presents challenges for both the Writing Development Initiative generally and the BAP specifically, but we feel these are outweighed by the benefits of having a Writing Across the Curriculum program that impacts over a third of the student body each year and has the support and participation of dozens of instructors. Our inclusive approach to writing support has both strengths and weaknesses, but it is a political necessity that requires an equally inclusive and diverse approach to assessment. Furthermore, the WDI as a whole operates with a centripetal approach: our faculty partners bring projects to us, we do not bring our projects to them. Our "one size doesn't fit all" approach to assessment ensures that assessment, as well as project design, fits into this larger mandate.

\section{Conclusion}

The BAP has already helped put the assessment of WDI projects on a more solid footing, and has brought improvements in pedagogical understanding and practice to many courses across the disciplinary spectrum. While it has limitations, it is nonetheless a valuable tool in our ongoing drive to embrace, enhance and use assessment.

Our assessment program is successful, in part, because of the financial and political support it receives from our university's administration. We believe we have earned this support through years of building the WDI, emphasizing and educating others about the importance of assessment. It has become a very positive loop: by taking assessment seriously, we helped build a context in which others took it seriously too, and now that context is generating pedagogical developments and research on its own. The WDI's assessment process started very modestly, almost 15 years ago, with a simple questionnaire distributed to participating instructors at the end of term; it has grown into something rigorous and productive. To return again to Isabelle Thompson: writing when the WDI was still in its infancy, she described what we have found in the past year or two with the BAP: "this requirement for accountability can also become an impetus for change, a vehicle for testing established practices and conducting meaningful research, and a means for gaining as well as using power. Assessment can bring opportunities as well as accountability for writing centres" (53).

\section{Endnotes}

1. To this end, there is the option for the WDI Committee to recommend that the WDI project funding become part of the course's base budget, in cases where projects have attained stability, have demonstrated success, and have departmental support. 
Volume 29, 2019

http://journals.sfu.ca/cjsdw

\section{References}

Brooks, K. (2002). National culture and the first-year English curriculum: An historical study of composition' in Canadian universities. The American Review of Canadian Studies, 32, 673-94.

CCCC Committee on Assessment. (2014). Writing Assessment: A Position Statement. Retrieved from https://cccc.ncte.org/cccc/resources/positions/writingassessment

Cyr, D., Childs, R., \& Elgie, S. (2013). Recruiting students for research in postsecondary education: A guide. Toronto: Higher Education Quality Council of Ontario.

Elliot, N. \& Perelman, L. (2012). Writing assessment in the 21st century: Essays in honor of Edward M. White. New York: Hampton Press.

Fulwiler, T. (1988). Evaluating writing across the curriculum programs. New Directions for Teaching and Learning, 61-75.

Graves, R. (1994). Writing instruction in Canadian universities. Winnipeg, MB: Inkshed.

Graves, R. \& Graves, H. (2006). Composition in Anglo-Canadian universities: Past, present, and future. In R. Graves and H. Graves (Eds.), Writing Centres, Writing Seminars, Writing Culture: Writing Instruction in Anglo-Canadian Universities (pp. 1-22). Winnipeg, MB: Inkshed.

Hubert, H. (1994). Harmonious perfection: The development of English studies in nineteenth-century Anglo-Canadian colleges. East Lansing: Michigan State University Press.

Hubert, H. (1994b). A history of college rhetoric in the U.S. and Canada: Different traditions." In S.P. Baardman, S.B. Straw, and L.E. Atkinson. (Eds.). Social Reflections on Writing: To Reach and Realize. (pp. 13-31). Winnipeg: Literacy Publications.

Hubert, H. \& Garrett-Petts, W. (2006). The rhetoric of 'Intelligent Recreation': An historical narrative of English studies in Canada. In R. Graves and H. Graves (Eds.), Writing Centres, Writing Seminars, Writing Culture: Writing Instruction in Anglo-Canadian Universities (pp. 61-94). Winnipeg, MB: Inkshed.

Hunt, R. (2006). Writing under the curriculum. In R. Graves and H. Graves (Eds.), Writing Centres, Writing Seminars, Writing Culture: Writing Instruction in Anglo-Canadian Universities (pp. 371383). Winnipeg, MB: Inkshed.

Huot, B. (1996). Toward a new theory of writing assessment. College Composition and Communication, 47, 4, 549-566.

International Network of Writing Across the Curriculum Programs. (2014). Statement of WAC Principles and Practices. Retrieved from http://wac.colostate.edu/principles/statement.pdf 
Volume 29, 2019

http://journals.sfu.ca/cjsdw

Johnson, N. (2006). Rhetoric and belles lettres in the Canadian academy: An historical analysis. In R. Graves and H. Graves (Eds.), Writing Centres, Writing Seminars, Writing Culture: Writing Instruction in Anglo-Canadian Universities (pp. 61-94). Winnipeg, MB: Inkshed.

Kearns, J. \& Turner, B. (2008). The historical roots of writing instruction in Anglo-Canadian universities. Zeitschrift Schreiben, 1, 7, 1-8.

O'Neill, P., Moore, C., Huot, B. (2009). A Guide to college writing assessment. University Press of Colorado. Retrieved from http://www.jstor.org/stable/j.ctt4cgrbz.

Procter, M. (2011). Talking the talk and walking the walk: Establishing the academic role of writing centres. In D. Starke-Meyerring et al (Eds.), Writing in Knowledge Societies. (pp. 415-439). Fort Collins, CO: The WAC Clearinghouse.

Pruchnik, J. et al. (2018). Slouching towards sustainability: Mixed methods in the assessment of student writing. Journal of Writing Assessment, 11,1.

Smith, T. (2006). Recent trends in writing instruction and composition studies in Canadian universities. In R. Graves and H. Graves (Eds.), Writing Centres, Writing Seminars, Writing Culture: Writing Instruction in Anglo-Canadian Universities (pp. 319-356). Winnipeg, MB: Inkshed.

Thompson, I. (2006). Writing center assessment: Why and a little how. Writing Center Journal, 26, 1, 33-61.

Yancey, K. B. \& Huot, B. (Eds.) (1997). Assessing writing across the curriculum: Diverse approaches and Practices. Greenwich: Ablex. 